\title{
Prenatal alcohol exposure affects developmental differentiation of interictal discharges in septal and temporal hippocampus
}

\author{
MARIA-ELENI EVANGELAKI", CATERINA PSARROPOULOU* \\ Laboratory of Animal and Human Physiology, Dept. of Biological Applications and Technology, \\ Faculty of Health Sciences, University of Ioannina, Ioannina, Greece
}

\begin{abstract}
Prenatal alcohol exposure (PAE) provokes lifelong CNS dysfunction, including an increased susceptibility to seizure disorders. We investigated hippocampal excitability in vitro in the offspring of dams exposed to a mild ethanol concentration throughout pregnancy (ethanol $15 \% \mathrm{v} / \mathrm{v}$ in drinking water). Hippocampal slices were prepared from the offspring at a young (Y, 21-30 postnatal days, PND) or adult (A, 60 PND) age, with controls from same age normal rats (N). Synchronous spontaneous interictal-type epileptiform discharges (IEDs) were induced by bathing the slices in $\mathrm{Mg}^{2+}$-free ACSF or in 4-Aminopyri-

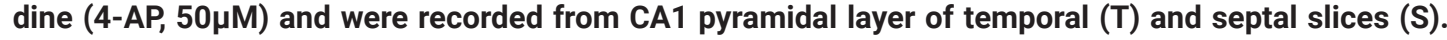
Hippocampal slices readily generated IEDs following NMDA receptor activation or $\mathrm{K}^{+}$conductance block, with frequency and duration depending on location (septal or temporal), age, the activating mechanism, and prior conditioning ( $\mathrm{N}$ or PAE). From the two media, 4-AP induced higher frequency (always), shorter duration (mostly) IEDs compared to $\mathrm{Mg}^{2+}$-free ACSF. Temporal IED frequency increased with age, whereas septal was stable, indicating an earlier maturation of the latter part. The hippocampal " $T$ to $S$ " (high to low) excitability gradient appeared at/later than the end of the first postnatal month and mostly concerned discharge frequency. Discharge duration generally decreased with maturation but appeared to depend on many factors, including conditioning. Prenatal alcohol exposure differentiated the control of synchronous discharges by NMDA receptors and $\mathrm{K}^{+}$conductances, and their developmental evolution, thus suggesting potential mechanisms for aberrant hippocampal neuronal network function.
\end{abstract}

KEYWORDS: Fetal Alcohol Syndrome, maturation, $\mathrm{K}^{+}$homeostasis, NMDA receptors

\section{Introduction}

Seizures are more common in people with developmental disabilities (Lindblom et al., 2001; Camfield and Camfield, 2007) including "Fetal Alcohol Syndrome" (FAS, or Fetal Alcohol Syndrome Disorders, FASD). FAS describes the host of dysfunctions occurring in children exposed prenatally to ethanol (Prenatal Alcohol Exposure, PAE), several of which have their origin in CNS. Seizure incidence is higher by as much as $21 \%$ in the FAS or FASD population (Spohr and Steinhausen, 1987; O'Malley and Barr, 1998; Bell et al., 2010). PAE damages the hippocampus, causing problems with learning and memory (Blanchard et al., 1987; Berman and Hannigan, 2000; Dodge et al., 2020).

Hippocampal input, output and neurotransmitter receptor complement differs along its longitudinal axis, resulting in functional differences in intrinsic neurocircuits (Papatheodoropoulos, 2002;
Papatheodoropoulos and Kostopoulos, 2002; Papatheodoropoulos et al., 2005). Septal hippocampus is involved in spatial memory and learning (Moser and Moser, 1998; Jones and McHugh, 2011), whereas the temporal extremity is involved in stress response and emotion processing (Adhikari et al., 2010; Fanselow and Dong, 2010), at the same time manifesting a low threshold for epileptic discharges (Gilbert et al., 1985; Papatheodoropoulos et al., 2005; Fanselow and Dong, 2010; Toyoda et al., 2013). The hippocampus undergoes significant anatomical and functional changes during the first postnatal month (Schwartzkroin, 1982; Schwartzkroin et al., 1982), resulting in different patterns of activity over time (Gómez and Edgin, 2016).

Abbreviationsused in this paper:FAS, Fetal Alcohol Syndrome; NMDA, N-methylD-aspartate; PAE, Prenatal Alcohol Exposure.

\footnotetext{
*Address correspondence to: Caterina Psarropoulou. Dept. of Biological Applications and Technologies, University of Ioannina, Ioannina, Greece. Tel: (26510) 07345. E-mail: cpsarrop@uoi.gr | https://orcid.org/0000-0002-1929-6951

${ }^{\#}$ Current address: Laboratory of Physiology, Dept. of Medicine, Aristotle University of Thessaloniki, Thessaloniki, 54124, Greece.
} 
We studied developmental patterns of synchronous activity in the hippocampus, by provoking spontaneous epileptiform interictal-like discharges (IEDs) with perfusion of $\mathrm{Mg}^{2+}$-free ACSF or 4-aminopyridine (4-AP, $50 \mu \mathrm{M})$ in separate sets of experiments and by recording IED frequency and duration from the CA1 pyramidal layer of septal (S) or temporal ( $T$ ) hippocampal slices from Normal $(\mathrm{N})$ or Prenatal Alcohol Exposure (PAE) rats. We used two age windows: young ( $Y$, postnatal days 21-35) and adult (A, postnatal days 90-120). In a third set of experiments, we tested the effects of increasing extracellular $\mathrm{K}^{+}$to $7 \mathrm{mM}$, a condition occurring following intense neuronal activity, which further increases network excitability. Here we report differences between the response of $\mathrm{N}$ and PAE slices to the activation of different synchronizing mechanisms (NMDA receptors or $\mathrm{K}^{+}$channel block), and furthermore, differences in the developmental evolution between $S$ and $T$ slices leading to differences in the $T$ to $S$ excitability gradient, all factors that may influence physiological and pathophysio-logical hippocampal function.

\section{Results}

Spontaneous IEDs in hippocampal slices of young and adult rats

Perfusion with either $\mathrm{Mg}^{2+}$-free ACSF or 4-AP $(50 \mu \mathrm{M})$ induced the appearance of spontaneous synchronous interictal-like epileptiform discharges (IEDs) with stable rates of recurrence in all slices (previously quiescent). They consisted of a positive field potential, their "duration", with several negative going population spikes. In $\mathrm{Mg}^{2+}$-free ACSF, IED frequency ranged between $0.1-0.15 \mathrm{~Hz}$ (Y slices) and $0.16-0.4 \mathrm{~Hz}$ (A slices); IED duration ranged between 300-400 $\mathrm{ms}$ in all age groups. In 4-AP, IEDs had also regular rates of recurrence ranging between $0.4-0.6 \mathrm{~Hz}(Y$ slices) and $0.4-0.9 \mathrm{~Hz}$ (A slices), with IED duration between 100-500 ms (Y slices) and 100-130 ms (A slices). Representative slow speed recordings from all slice groups are shown in Fig. 1.

\section{IEDs in septal and temporal slices}

The mean values of IED frequency and duration recorded in $\mathrm{Mg}^{2+}$-free ACSF or in 4-AP are presented in the graphs of Fig. 2, where the order of columns is consistent, to facilitate comparisons. T \& S slices are paired throughout, on the left are data from $\mathrm{N}$ slices - first $Y$, then $A$ - and on the right PAE data in the same order. On the left $(A, C)$ are IED frequency graphs, on the right IED duration graphs $(B, D)$; upper graphs $(A, B)$ contain data from $\mathrm{Mg}^{2+}$-free ACSF, lower (C, D) from 4-AP.

In $\mathrm{Mg}^{2+}$-free ACSF, IED frequencies tended to be higher in Tvs Sslices, in three out of four groups (Y\&A N, A PAE, Fig. 2A). In Y-PAE slices, S IED frequency was higher than $T(p=0.04$, 1-tailed Student's t-test) Therefore, it is possible that the $T$ to $S$ gradient of (high to low) IED frequency develops later than this age window. IED duration tended to be significantly higher in $T$ vs $S$ slices, in three out of four groups (Y-N p=0.006, Y\&A PAE, with $\mathrm{p}=0.04$ (1-tailed) and $\mathrm{p}=0.009$ respectively, Fig. $2 \mathrm{~B})$. In adult $\mathrm{N}$ slices, this gradient is not observed; however, both columns
$(T, S)$ show higher than usual SEMs, discouraging any firm conclusions. IED frequency and duration mean values between $N$ \& PAE slices of same origin and age did not reveal any significant differences or trends.

In a different set of slices perfused with $50 \mu \mathrm{M} 4-\mathrm{AP}$, IED frequencies were higher in T vs S slices in 3 out of 4 groups, and significantly so in 2 out of 4 (A-N p =0.004, A-PAE $p=0.04$, 1-tailed Student's t-test Fig. 2C). IED duration (Fig. 2D) was similar in $T$ and $S$ slices in 3 out of 4 groups, namely A-N, Y-PAE and A-PAE. Contrary to trend, in the $\mathrm{Y}-\mathrm{N}$ group, mean IED duration was significantly lower in $\mathrm{T}$ vs $\mathrm{S}$ slices ( $p=0.03$; a large SEM in the latter is also noted). Resembling findings in $\mathrm{Mg}^{2+}$-free ACSF above, mean IED frequency \& duration between $N$ \& PAE slices of same origin and age did not reveal any significant differences or trends.

\section{Developmental IED changes}

IED frequency recorded from $T$ slices increased with age in all slices ( $N$ \& PAE in $\mathrm{Mg}^{2+}$-free ACSF or in 4-AP). The increase was significant in 3 out of 4 groups (in $\mathrm{Mg}^{2+}$-free ACSF: $\mathrm{N} p<0.0001$, PAE $p=0.001$, in 4-AP: $N p=0.03$, PAE $p=0.22$ (ns) Fig. 2 A,C). By contrast, $S$ slice IED frequency did not change with age, (N \& PAE slices, in $\mathrm{Mg}^{2+}$-free ACSF or in 4-AP).

The developmental evolution of IED duration was more complicated, since it seemed to depend on both the perfusion medium and animal conditioning. In $\mathrm{Mg}^{2+}$-free ACSF, IED duration remained (developmentally) stable in $\mathrm{N}$ slices but decreased in all PAE slices ( $\mathrm{T} p=0.03$, 1-tailed, $\mathrm{S} \mathrm{p}=0.02$, Fig. $2 \mathrm{~B}$ ). On the contrary, in 4-AP, a developmental decrease of IED duration was observed in $\mathrm{N}$ ( $T$ $p=0.003, S p=0.03$ ) slices but not in PAE slices (Fig. 2D).

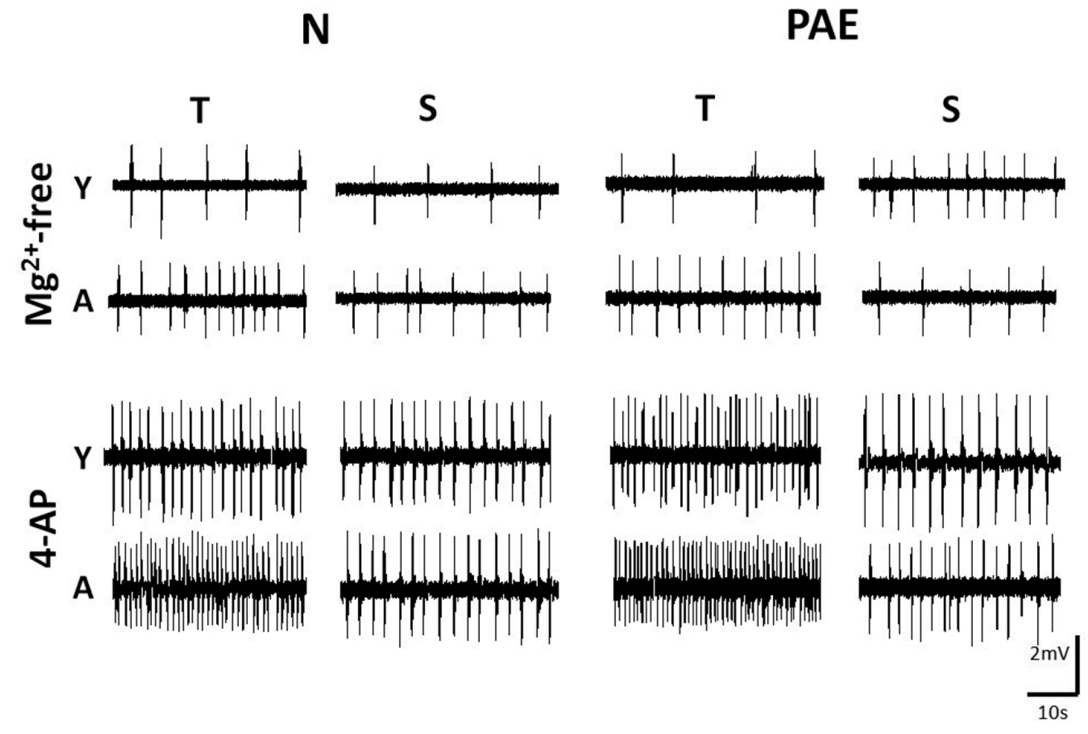

Fig. 1. Representative slow speed traces depicting IED frequency in slices of different origin, age window and conditioning, bathed in two media. Hippocampal slices were nonconditioned (Normal, N) or conditioned (Prenatal Alcohol Exposure, PAE), of Temporal (T) or Septal (S) origin, Young (Y) or Adult (A) and were bathed in $\mathrm{Mg}^{2+}$-free ACSF (upper set) or in $50 \mu \mathrm{M}$ 4-AP (lower set). The ages in PNDs of the animals from which the slices were taken were as follows. Mg $^{2+}$-free, upper set: N-Y-T 23, N-Y-S 26, N-A-T 100, N-A-S 98, PAE-Y-T 28, PAE-Y-S 22, PAE-A-T 102, PAE-A-S 105; 4-AP, lower set: N-Y-T 26, N-Y-S 31, N-A-T 93, N-A-S 110, PAE-Y-T 28, PAE-Y-S 25, PAE-A-T 95, PAE-A-S 98. Note the higher IED frequency in 4-AP vs $\mathrm{Mg}^{2+}$-free ACSF perfusion, in A vs Y slices and in T vs S slices. Calibration bars, $2 \mathrm{mV}$, 10 s. 
TABLE 1

\section{IED FREQUENCY (HZ) IN MG ${ }^{2+}$-FREE ACSF AND FOLLOWING EXTRACELLULAR $\mathrm{K}^{+}$INCREASE TO 7MM}

\begin{tabular}{|c|c|c|c|c|c|}
\hline & & & $\mathrm{Mg}^{2+}$ free & $\mathrm{K}^{+}(7 \mathrm{mM})$ & statistics \\
\hline \multirow{4}{*}{$\begin{array}{l}0 \\
5 \\
0 \\
\end{array}$} & \multirow{2}{*}{$\mathrm{N}$} & $\mathrm{T}$ & $0.32 \pm 0.08, n=6 / 5$ & $0.51 \pm 0.11, n=6 / 5$ & ns \\
\hline & & $S$ & $0.12 \pm 0.04, n=13 / 7$ & $0.53 \pm 0.1, n=13 / 7$ & $\star \star$ \\
\hline & \multirow{2}{*}{ PAE } & $\mathrm{T}$ & $0.15 \pm 0.03, n=5 / 4$ & $0.27 \pm 0.05, n=5 / 4$ & *1 tailed \\
\hline & & $\mathrm{S}$ & $0.14 \pm 0.04, n=5 / 4$ & $0.33 \pm 0.1 n=5 / 4$ & ns \\
\hline \multirow{4}{*}{ 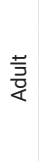 } & \multirow{2}{*}{$\mathrm{N}$} & $T$ & $0.38 \pm 0.11, n=7 / 5$ & $0.57 \pm 0.08, n=7 / 5$ & *1 tailed \\
\hline & & $\mathrm{S}$ & $0.16 \pm 0.08, n=4 / 3$ & $0.41 \pm 0.15, n=4 / 3$ & ns \\
\hline & \multirow[t]{2}{*}{ PAE } & $\mathrm{T}$ & $0.22 \pm 0.1, n=6 / 4$ & $0.45 \pm 0.08, n=6 / 4$ & ns \\
\hline & & $\mathrm{s}$ & $0.13 \pm 0.03, n=6 / 4$ & $0.59 \pm 0.07, n=6 / 4$ & ** \\
\hline
\end{tabular}

\section{Differences between the two in vitro models}

The use of two models with different IED activating mechanisms was intended to reveal excitability differences between $\mathrm{N}$ and PAE slices and /or in their developmental evolution. Results are presented in Fig. 3, where adjoining columns present results obtained in different media, from slices of same origin, age and conditioning, a rearrangement of Fig. 2 columns. IED frequency graphs are on the left $(A, C)$ and IED duration on the right $(B, D)$; upper graphs $(A, B)$ contain data from young slices, lower $(C, D)$ from adult.

IED frequencies recorded in 4-AP (blue columns) were significantly higher than those in $\mathrm{Mg}^{2+}$-free ACSF (white columns), a common trend in all slice groups, independently of origin $(T, S)$, age $(Y, A)$ or conditioning (N, PAE) (Fig. $3 A, C$ ).

Fig. 2. Comparison of IED frequency and duration in temporal vs septal hippocampal slices. Interictal discharge frequency $(A, C)$ and duration $(B, D)$ recorded in hippocampal CA1 from temporal $(T)$ and septal $(S)$, young $(Y)$ and adult (A, mosaic set), normal (white set) and prenatal alcohol exposure (PAE, pink set) slices, bathed in $\mathrm{Mg}^{2+}$-free ACSF (A,

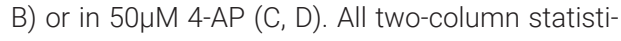
cal comparisons were made by the student's t-test for unpaired data (stated whenever 1-tailed, 1-tl). Comparisons not shown yielded p>0.05 (n.s.) (A) Bar chart of IED frequency in $\mathrm{Mg}^{2+}$-free ACSF. The numbers of slices/animals per column are: $\mathrm{N}-\mathrm{Y}-\mathrm{T}$ $n=34 / 17, N-Y-S n=12 / 7, N-A-T n=7 / 6, N-A-S n=4 / 3$, PAE-Y-T $n=57 / 27$, PAE-Y-S $n=5 / 4$, PAE-A-T $n=6 / 5$, PAE-A-S $n=6 / 5$ and apply also to $B$. IED frequency

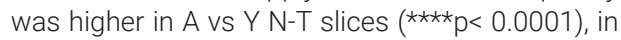
$S$ vs T PAE-Y slices ( ${ }^{*} \mathrm{p}=0.04$, 1-tailed) and in A vs Y PAE-T slices ( $\left.{ }^{\star \star} p=0.001\right)$. (B) Bar chart of IED duration of the slices shown in A. IED duration was longer in T vs S Y-N slices ( $\left.{ }^{*} \mathrm{p}=0.006\right)$, in T v S $\mathrm{Y}$ PAE slices ( ${ }^{*} p=0.04,1$-tailed) in T vs S A-PAE slices (** $p=0.009)$, in Y vs A T-PAE slices ( ${ }^{*} p=0.03,1$-tailed) and in $Y$ vs A S-PAE slices $\left({ }^{\star} p=0.02\right)$. (C) Bar chart of IED frequency in 4-AP $(50 \mu \mathrm{M})$. The numbers of slices/animals per column are: $\mathrm{N}-\mathrm{Y}-\mathrm{T} n=11 / 7, \mathrm{~N}-\mathrm{Y}-\mathrm{S}$ $n=5 / 4, N-A-T n=11 / 6, N-A-S n=7 / 5, P A E-Y-T n=7 / 5$, PAE-Y-S n=5/4, PAE-A-T $n=7 / 5$, PAE-A-S $n=6 / 4$ and

A

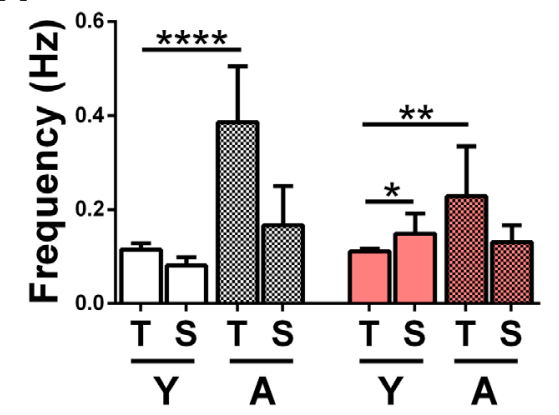

C

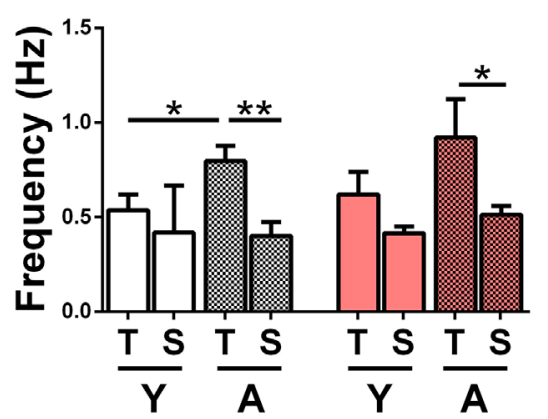

IED duration, however, appeared to depend on the perfusion media, but in a non-uniform way. In the $Y$ group (Fig. 3B), T slices had shorter IED duration in 4-AP vs in $\mathrm{Mg}^{2+}$-free $\mathrm{ACSF}(\mathrm{N}-\mathrm{T} \mathrm{p}=0.009$, PAE-T $p=0.02)$, while $S$ slices had longer $(N-S p=0.01)$ or equal (PAE-S) in the two media. In the A population, 3 out of 4 groups had shorter IED duration in 4-AP $(\mathrm{N}-\mathrm{T} \mathrm{p}=0.04, \mathrm{~N}-\mathrm{S}$ n.s., PAE-T $\mathrm{p}=0.04)$, while PAE-S slices had equal mean values in the two media (Fig. 3D). In other words, all T slices had shorter IED duration in 4-AP vs in $\mathrm{Mg}^{2+}$-free ACSF, while the response $S$ slices either reversed with age ( $\mathrm{N}$ slices having initially longer IEDs in 4-AP vs $\mathrm{Mg}^{2+}$-free ACSF, reversing with maturation) or remained unaltered (PAE slices). If the changes in $\mathrm{N}$ slices represent a physiological developmental trend, then it appears that PAE has "blocked" or inhibited it.

\section{High extracellular $\mathrm{K}^{+}(7 \mathrm{mM})$ in $\mathrm{Mg}^{2+}$-free ACSF}

Synchronous neuronal activity causes transient local increases in extracellular $\mathrm{K}^{+}$, which may in turn increase excitability, by reducing in-out $\mathrm{K}^{+}$gradient and thus by blocking $\mathrm{K}^{+}$conductances, for as long as they last. Increasing extracellular $\mathrm{K}^{+}$concentration to $7 \mathrm{mM}$ in $\mathrm{Mg}^{2+}$-free ACSF increased IED frequency in all slices, as detailed in Table 1; a uniform trend although not statistically significant in all groups. High $\mathrm{K}^{+}$had neither consistent nor significant effects on IED duration, so data were not included in the table.

The percent IED frequency increase in high $\mathrm{K}^{+}$is illustrated in the graphs of Fig. 4. In the graph of Fig. 4A the $\mathrm{K}^{+}$effect has been plotted in T vs S slices of all groups ( $Y, A, N, P A E)$. In the $Y-N$ slices, IED frequency increase was more pronounced in the $S$ vs $T$ slices $(p=0.03,1$-tailed), whereas in the Y-PAE, it was similar. In the A population, no difference between $T$ \& $S$ slices was observed in any group. To compare developmental trends in N vs PAE slices,

apply also to D. IED frequencies were higher in T vs S slices in N-A (**p=0.004), and in PAE-A ( ${ }^{*} \mathrm{p}=0.04,1$-tailed) and also in A vs $Y$ N-T slices (* $\left.p=0.03\right)$. (D) Bar chart of IED duration of the slices shown in C. IED duration was longer in S vs T Y-N slices ( ${ }^{\circ} p=0.03$ ), in Y vs A N-T slices (**p=0.003), in Y vs A N-S slices ( ${ }^{\star} p=0.03$ ) and in PAE vs N A-T slices ( ${ }^{\star} p=0.03$, 1-tailed). 
A

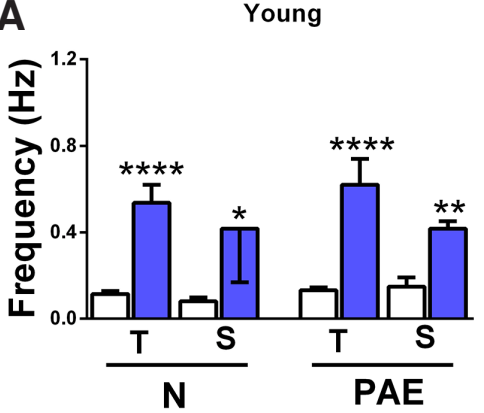

C

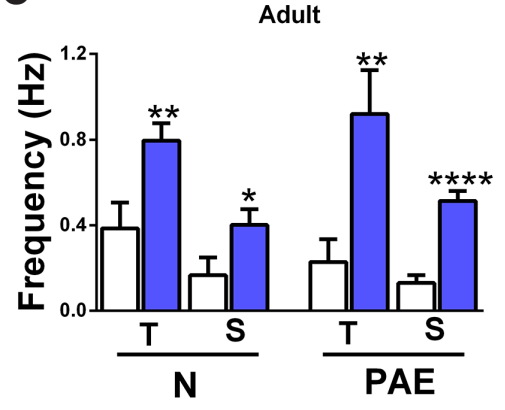

B

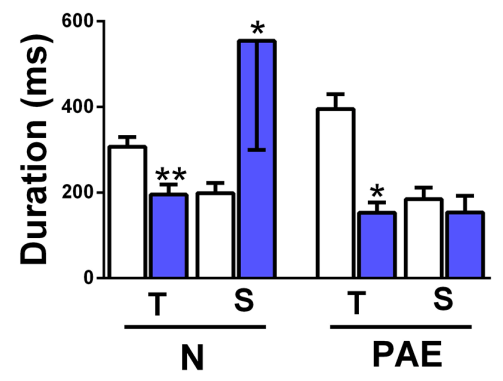

D

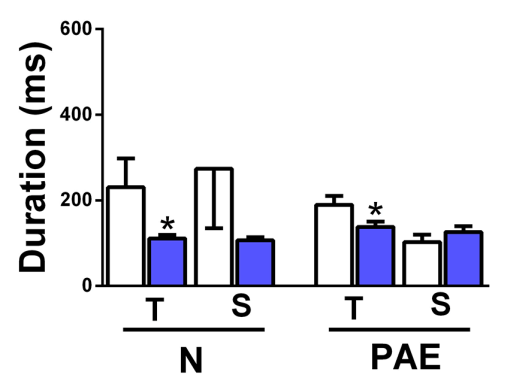

Fig. 3. Comparison of IED frequency and duration in the two media. IED frequency $(A, C)$ and duration $(B, D)$ mean values were obtained in $\mathrm{Mg}^{2+}$-free ACSF ( $\mathrm{i}$, white columns) or in 4-AP (ii, blue columns). (A) IED frequency in young slices. The numbers of slices/animals per column are N-T-(i) $n=34 / 17, N$-T-(ii) $n=11 / 7, N-S-$-(i) $n=12 / 7, N-S-$ (ii) $n=5 / 4$, PAE-T-(i) $n=57 / 27$, PAET-(ii) $n=7 / 5$, PAE-S-(i) $n=5 / 4$, PAE-S-(ii) $n=5 / 4$ and apply to graph $B$ as well. All slice groups had higher IED frequencies in 4-AP vs in $\mathrm{Mg}^{2+}$-free ACSF: N-T ${ }^{* \star *}{ }^{*} \mathrm{p}<0.0001, \mathrm{~N}-\mathrm{S}{ }^{*} \mathrm{p}=0.04$, PAE-T $\star \star \star \star x p<0.0001$, PAE-S ${ }^{\star *} p=0.001$. (B) IED duration of the young slices shown in $A$. T slices (N, PAE) had longer IED duration in $\mathrm{Mg}^{2+}$-free ACSF vs in 4-AP (N-T**p=0.009, PAE- $\left.T{ }^{*} p=0.02\right)$. $\mathrm{N}$-S slices showed shorter IED duration in $\mathrm{Mg}^{2+}$-free ACSF vs in 4-AP (N-S* $\mathrm{P}=0.01)$, while PAE-S slices had similar IED duration in both media. (C) IED frequency in adult slices. The numbers of slices/animals per column are $\mathrm{N}$-T-(i) $n=7 / 6, N$-T-(ii) $n=11 / 6$, N-S-(i) $n=4 / 3, N$-S-(ii) $n=7 / 4$, PAE-T-(i) $n=6 / 5$, PAE-T-(ii) $n=7 / 5$, PAE-S-(i) $n=6 / 5$, PAE-S-(ii) $n=6 / 4$ and apply to graph $D$ as well. All slice groups had higher IED frequencies in 4-AP vs in $\mathrm{Mg}^{2+}$ free ACSF: $N-T{ }^{*} p=0.009, N-S * p=0.031$-tailed, PAE-T** $p=0.01$, PAE-S**** $<<0.0001$. (D) IED duration of the adult slices shown in C. T slices ( $N$, PAE) had longer IED duration in $\mathrm{Mg}^{2+}$-free ACSF vs in 4-AP ( $N-T * p=0.04$, PAE-T $\left.{ }^{*} p=0.04\right)$. N-S slices showed the same trend but without statistical significance, while PAE-S slices had similar IED duration in both media. we further plotted data separately for $\mathrm{T}$ and $\mathrm{S}$ slices. These demonstrated, first that the high $\mathrm{K}^{+}$effect was age-independent in the $\mathrm{N}-\mathrm{Y}$ and second that it increased with age in the PAE-T slices (difference of adult mean values $\mathrm{p}=0.03$, 1-tailed t-test; supported also by the significantly different slope of the line connecting mean values, $\mathrm{p}=0.03$, Fig. $4 \mathrm{~B}$ ). In $\mathrm{S}$ slices, the high $\mathrm{K}^{+}$effect decreased with age in the $\mathrm{N}$ population and increased in the PAE (Fig. 4C). Thus, the high $\mathrm{K}^{+}$experiment revealed a developmental differentiation between $\mathrm{N} \& \mathrm{PAE}$ of both $\mathrm{T} \& \mathrm{~S}$ origin.

\section{Discussion}

\section{Main findings}

All hippocampal slices readily generated synchronous interictallike discharges following NMDA receptor activation or $\mathrm{K}^{+}$conductance block, with frequency and duration depending on location (septal or temporal), age, the activating mechanism, and prior conditioning ( $\mathrm{N}$ or PAE). Synchronous discharge frequency increased at/later than the end of the first postnatal month in temporal hippocampus, but (apparently) earlier in septal. The hippocampal "T to $S$ " (high to low) excitability gradient appeared at this time and mostly concerned discharge frequency. Discharge duration generally decreased with maturation but appeared to depend on more factors than frequency. Prenatal alcohol exposure provoked differences between N \& PAE slices in the control of synchronous discharges by NMDA receptors and $\mathrm{K}^{+}$conductances, and also in their developmental evolution, thus suggesting potential mechanisms for aberrant hippocampal function.

\section{General}

Mild but continuous exposure to alcohol throughout gestation (the concentration given in drinking water corresponding to a BAC level of 120 mg/dl (Allan et al., 2003; Choi et al., 2005; Patten et al., 2014) generated offspring showing in vitro hippocampal excitability differences from controls, thus corroborating clinical studies which suggest that even mild alcoholism may have negative and long-term effects on brain development (leraci and Herrera, 2007; Kesmodel et al., 2019).

Early differences between $N$ \& PAE slices in IED frequency and duration were further modified by development. Some of the early findings may be related to alcohol withdrawal, since the dam stopped receiving ethanol via the drinking water at PND 15 of offspring (see also Paula-Barbosa et al., 1993)). Indeed, some of the early changes observed in PAE brain, which may be a combination of factors, including reduced neurogenesis, synaptogenesis and decreased cell and spine density (Tarelo-Acuña et al., 2000; Livy et al., 2003; Cullen et al., 2014), have been found to normalize with age (Abbott et al., 2016).

We have examined the dependence of IED frequency and duration on several factors, and as a result, the slice number is modest in some groups. To mitigate the possible error that this might introduce, care was taken to include slices from different animals, and in most cases, data analysis yielded small SEMs of mean values, permitting meaningful comparisons with statistical significance or clear trends. In addition to this, we made every effort to combine different lines of evidence for our conclusions and to be conservative in our interpretation/speculations.

\section{Hippocampal development}

\section{$\mathrm{Mg}^{2+}$-free ACSF vs 4-AP perfusion}

Perfusion with $\mathrm{Mg}^{2+}$-free ACSF provoked uniformly lower IED frequency compared with 4-AP (all slice groups, Fig. 3 A,C), suggesting that NMDA receptors as the main IED generating mechanism produce lower frequency discharges compared to $\mathrm{K}^{+}$conductance block (by 4-AP). Unlike IED frequency, IED duration was not uniformly affected by the activating mechanism, indicating that other factors may carry more weight in controlling synchronous discharge length.

$\mathrm{Mg}^{2+}$-free ACSF induced longer (duration) IEDs than 4-AP in most slice groups ( 200-300ms, Fig. 2B vs <200ms Fig. 2C); specifically, 
TABLE 2

\section{DEVELOPMENTAL CHANGES IN IED FREQUENCY AND DURATION}

\begin{tabular}{cccccc} 
& & \multicolumn{2}{c}{ IED frequency } & \multicolumn{2}{c}{ IED duration } \\
\cline { 3 - 6 } & & Mg $^{2+}$-free ACSF & 4-AP & $\mathbf{M g}^{2+}$-free ACSF & 4-AP \\
\hline \multirow{2}{*}{$\mathrm{T}$} & $\boldsymbol{\Delta}$ & $\boldsymbol{\Delta}$ & $\boldsymbol{\nabla}$ & $\boldsymbol{\nabla}$ \\
& $\mathrm{PAE}$ & $\boldsymbol{\Delta}$ & $\boldsymbol{\Delta}$ & $\boldsymbol{\nabla}$ & $=$ \\
\hline \multirow{2}{*}{$\mathrm{S}$} & $\mathrm{N}$ & $=$ & $=$ & $=$ & $\boldsymbol{\nabla}$ \\
& $\mathrm{PAE}$ & $=$ & $=$ & $\boldsymbol{\nabla}$ & $=$ \\
\hline
\end{tabular}

Pairs of changes differing between N \& PAE slices are shaded in grey

Black arrowheads signify significant $(p<0.05)$ changes, grey arrowheads signify trends

all T slices showed longer IEDs (Fig. 3 B,D) suggesting that NMDA receptor activation may be more important compared to the inhibition of $\mathrm{K}^{+}$conductances in controlling the length of synchronous discharges there. In S (PAE) slices, IED duration was similar in the two media, suggesting similar potency of either mechanism in supporting synchronous discharge length. In S (N) slices, block of $\mathrm{K}^{+}$conductances generated longer IEDs than NMDA receptor activation in young slices, whereas the opposite was true in adult slices (Fig. 3 B,D). This developmental change is interpreted with caution because of the large variability of the data. A similar septal ( $\mathrm{N}$ ) data variability in the high $\mathrm{K}^{+}$experiments (Fig. 4A) prompted the question whether this resulted from some physiological unknown at this time factor. Interestingly, such variability was absent from PAE-S slices, despite the similar sample size.

IED frequency and duration in Temporal and Septal slices

IED frequency increased between 21-35 and 90-120 PNDs in $\mathrm{T}$ slices, a stronger trend in $\mathrm{N}$ slices and a weaker in PAE. No corresponding change was observed in S slices, suggesting that septal CA1 circuits reach their adult dynamics earlier than their temporal counterparts, and moreover that this developmental process is not affected by PAE; these results are schematically presented in Table 2.

A developmental IED duration decrease was observed in all $\mathrm{N}$ slices bathed in 4-AP (see also (Psarropoulou and Avoli, 1996))

Fig. 4. Effect of the increase of extracellular $\mathrm{K}^{+}$concentration to $7 \mathrm{mM}$ in $\mathbf{M g}^{2+}$-free ACSF. (A) Percent IED frequency increase in T and S slices from $Y$ (left side) and A (right side, mosaic set) N (white set) and PAE (pink set) animals. The numbers of slices/animals per column were $\mathrm{Y}$ : N-T $n=6 / 5, \mathrm{~N}-\mathrm{S}$ $n=13 / 7$, PAE-T $n=5 / 4$, PAE-S n=5/4, A: N-T n=7/5, N-S n=4/3, PAE-T $n=6 / 4$, PAE-S $n=6 / 4$ and statistical comparisons were made between adjacent pairs of columns as shown by the unpaired student's t-test. Young slices, left side of graph: high $\mathrm{K}^{+}$had a stronger effect in N-S vs $\mathrm{N}$-T slices ( ${ }^{*} \mathrm{p}=0.03$, 1-tailed); the effect in PAE (T, S) was similar. Adult slices, right side of graph: High $\mathrm{K}^{+}$caused similar effects all groups. In N T slices, the high $\mathrm{K}^{+}$effect was similar between $Y$ (left side of graph, white set) vs A (mosaic), while in PAE it increased with age $\left({ }^{*} \mathrm{p}=0.03,1\right.$-tailed). In N $\mathrm{S}$, the high $\mathrm{K}^{+}$effect decreased with age in $\mathrm{N}$ slices (although the difference was not statistically significant), while it increased with age in PAE slices ( $\left.{ }^{*} p=0.03\right)$. (B) This plot illustrates the developmental change of the effect in $\mathrm{N}$-T slices (continuous line) vs this of PAE-T slices (dashed line). The high $\mathrm{K}^{+}$effect is independent of age in $\mathrm{N}-\mathrm{T}$ slices, while it increases with age in the PAE-S slices. The two lines had significantly different slopes $\left({ }^{\star} p=0.03\right)$. (C) This plot illustrates the developmental change of the high $\mathrm{K}^{+}$effect in $\mathrm{N}$-S slices (continuous line) vs this of PAE-S slices (dashed line). In N-S slices, the $\mathrm{K}^{+}$effect decreases with age, while in PAE-S slices it increases, nevertheless the comparison of the slopes yielded a $p>0.05$. and in all PAE slices bathed in $\mathrm{Mg}^{2+}$-free ACSF (downward arrows in Table 2), suggesting a developmental reduction of 4-AP-sensitive $\mathrm{K}^{+}$conductances in the former ( $\mathrm{N}$ slices) and of NMDA receptor excitability in the latter (PAE slices). Although discharge length is controlled by several mechanisms, not assessed here, these developmental differences may underlie some of the PAE effects.

Combining the above, it also follows that developmental changes in IED frequency \& duration are to some extent independent, since they are not parallel.

Temporal to Septal excitability gradient

Results comparing $\mathrm{T}$ and $\mathrm{S}$ slice responses through maturation are schematically presented in Table 3 , to facilitate discussion of the excitability gradient between the two poles. IED frequency was similar in $T$ \& $S$ young slices and became significantly higher in adult slices in both models, suggesting that the $T$ to $S$ excitability gradient (Mikroulis and Psarropoulou, 2012; Mikroulis et al., 2018) was developed at the end of or later than the first postnatal month, independently of the IED generating mechanism. There was not a clear $\mathrm{T}$ to $\mathrm{S}$ gradient regarding IED duration. In young slices, this gradient was observed during NMDA receptor activation but not $\mathrm{K}^{+}$conductance block; however, in adult slices it was mostly absent (Table 3). Taken together, these data suggest that NMDA receptors contribute to T vs S excitability gradient by enhancing IED duration in young hippocampus or IED frequency in adult. Second, $\mathrm{K}^{+}$conductance block (by 4-AP) seems to contribute to the T to $S$ excitability gradient in adult hippocampus only by enhancing IED frequency (Table 3). In conclusion, the $T$ to $S$ excitability gradient mostly concerns IED frequency, appears at the end of the first postnatal month, and is influenced to a minor degree by the IED generating mechanism.

A

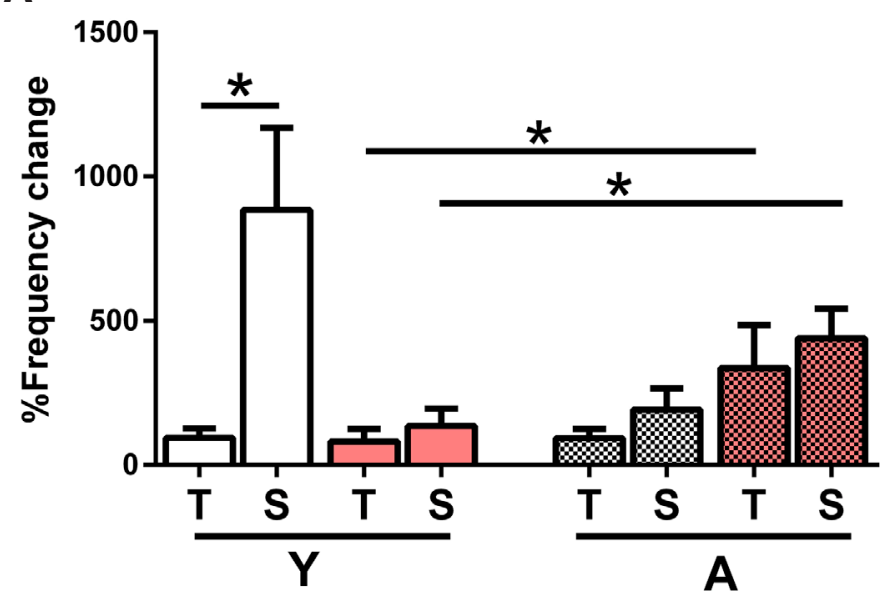

B

C
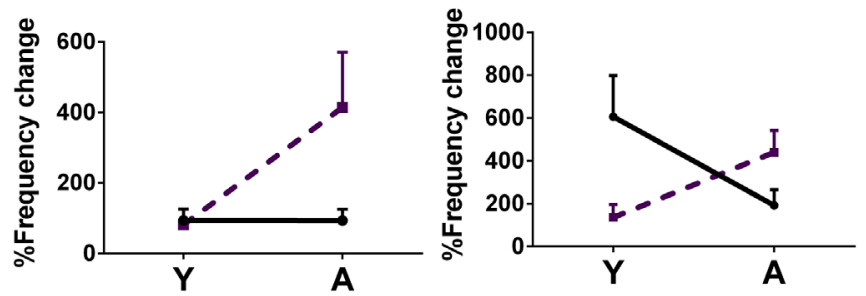
Response to high $\mathrm{K}^{+}$in $\mathrm{Mg}^{2+}$-free ACSF

Extracellular $\mathrm{K}^{+}$increases in the aftermath of intense synchronized activity, enhancing transiently excitability, until its redistribution by glial cells (Kofuji and Newman, 2004). Raising extracellular $\mathrm{K}^{+}$to $7 \mathrm{mM} \mathrm{in} \mathrm{Mg}^{2+}$-free ACSF increased spontaneous IED frequency, a particularly pronounced effect in the N-Y-S slices (Fig. 4) and increasing developmentally in all PAE, but not $\mathrm{N}$ slices (Fig. $4 \mathrm{~B}, \mathrm{C}$ ).

The first point: IED frequency increase in $\mathrm{N}$-Y-S slices was larger than in N-Y-T slices (Fig. 4A), although both groups had similar IED frequencies in 4-AP (Fig. 2C). These findings suggest the presence of some 4-AP-insensitive $\mathrm{K}^{+}$conductances in $\mathrm{N}-\mathrm{Y}$-S slices. Furthermore, the high $\mathrm{K}^{+}$effect was observed during NMDA receptor activation, which facilitates $\mathrm{Ca}^{2+}$ entry to neurons; we therefore suggest that these may be $\mathrm{Ca}^{2+}$-activated $\mathrm{K}^{+}$conductances.

In a similar line of thinking, the developmental increase of the high $\mathrm{K}^{+}$effect in PAE slices (Fig. 4A), and the absence of such a (developmental) effect in 4-AP (Fig. 2C), indicate the presence of 4-AP-insensitve $\mathrm{K}^{+}$conductances in adult PAE slices, likely $\mathrm{Ca}^{2+}$ activated $\mathrm{K}^{+}$conductances, as suggested above.

\section{PAE-induced functional changes}

We detected differences between N \& PAE hippocampal slices of a rather dynamic nature, related also to maturation, which we summarize in the following paragraphs.

4-AP provoked longer IED discharges in N-Y-S (vs T) slices, but equal in PAE (Table 3, grey areas); in addition, the high $\mathrm{K}^{+}$effect (in $\mathrm{Mg}^{2+}$-free ACSF) was stronger in $\mathrm{N}-\mathrm{Y}$-S slices vs the PAE ones (Fig. 4A). Both these findings suggest the decrease of hyperpolarizing $\mathrm{K}^{+}$conductances in young PAE septal hippocampus that could conceivably affect signal integration (mnemonic processes) and/ or pathophysiology.

4-AP-induced IED duration decreased with maturation in all $\mathrm{N}$ slices but not in PAE slices (Table 2, grey areas), indirectly suggesting the presence of more 4-AP-sensitive $\mathrm{K}^{+}$conductances in the latter. Furthermore, the high $\mathrm{K}^{+}$effect (in $\mathrm{Mg}^{2+}$-free ACSF) increased significantly with maturation in all PAE slices, indicating the presence of a strong complement of $\mathrm{K}^{+}$conductances, including $\mathrm{Ca}^{2+}$-activated and/or 4-AP insensitive ones (rationale given earlier). Taken together, these findings suggest the presence of strong hyperpolarizing $\mathrm{K}^{+}$conductances in mature PAE hippocampus; probably an adaptive change, which, however, if blocked, would lead to further excitation.

NMDA-receptor dependent IED duration did not change with maturation in N-S slices but decreased in PAE-S (Table 2 grey areas). In the same setting ( $\mathrm{Mg}^{2+}$-free ACSF), IED duration was equal in adult N (T\&S) slices but longer in T vs S adult PAE slices (Table 3 , grey areas). Taken together, these findings suggest a steeper $\mathrm{T}$ to $\mathrm{S}$ excitability gradient in adult PAE hippocampus vs $\mathrm{N}$ that may alter physiological processes and/or seizure threshold. The changes could be related to several factors: for example, altered NMDA receptor number or localization and/or subunit composition, which remain to be determined.

\section{Concluding Remarks}

This in vitro study demonstrated detectable changes in hippocampal synchronous discharges and their development, following mild but continuous prenatal ethanol exposure. Differences between N \& PAE slices in the control of synchronous discharges
TABLE 3

\section{DEVELOPMENTAL CHANGES IN TEMPORAL TO SEPTAL EXCITABILITY GRADIENT}

\begin{tabular}{cccccc} 
& & \multicolumn{2}{c}{ IED frequency } & \multicolumn{2}{c}{ IED duration } \\
\cline { 3 - 6 } & & $\mathbf{M g}^{2+}$-free ACSF & 4-AP & $\mathbf{M g}^{2+}$-free ACSF & 4-AP \\
\hline \multirow{2}{*}{$\mathbf{Y}$} & $\mathrm{N}$ & $\mathrm{T}=\mathrm{S}$ & $\mathrm{T}=\mathrm{S}$ & $\mathrm{T}>\mathrm{S}$ & $\mathrm{T}<\mathrm{S}$ \\
& $\mathrm{PAE}$ & $\mathrm{T}<\mathrm{S}$ & $\mathrm{T}=\mathrm{S}$ & $\mathrm{T}>\mathrm{S}$ & $\mathrm{T}=\mathrm{S}$ \\
\hline \multirow{2}{*}{$\mathrm{A}$} & $\mathrm{N}$ & $\mathrm{T}>\mathrm{S}$ & $\mathrm{T}>\mathrm{S}$ & $\mathrm{T}=\mathrm{S}$ & $\mathrm{T}=\mathrm{S}$ \\
& $\mathrm{PAE}$ & $\mathrm{T}>\mathrm{S}$ & $\mathrm{T}>\mathrm{S}$ & $\mathrm{T}>\mathrm{S}$ & $\mathrm{T}=\mathrm{S}$ \\
\hline
\end{tabular}

Pairs of changes differing between N \& PAE slices are shaded in grey

Black arrowheads signify significant $(p<0.05)$ changes, grey arrowheads signify trends

by NMDA receptors and $\mathrm{K}^{+}$conductances, and in particular their developmental evolution, suggest potential mechanisms for aberrant hippocampal function following prenatal alcohol exposure. Some of the PAE-induced changes were concentrated in septal hippocampus, so we speculate that mnemonic (learning) processes might be affected. It is unclear at this point whether these changes would also contribute to reducing seizure threshold. The development of more $\mathrm{K}^{+}$conductances (likely 4-AP-insensitive) in adult PAE hippocampus may represent adaptation, aimed at neutralizing increased excitability, although their block following a physiological extracellular $\mathrm{K}^{+}$increase would further enhance excitation.

\section{Material and Methods}

\section{Animals}

Experimental animals were Sprague-Dawley rats, housed three per cage at the University of Ioannina Animal Facility, with free access to pellet food and water and a $12 \mathrm{~h}$ light/dark cycle. Animal treatment and experimental procedures were conducted in accordance with the Directive of the European Parliament and of the Council of 22 September 2010 on the protection of animals used for scientific purposes (2010/63/EE) and approved by the Prefectural (Epirus) Animal Care and Use Committee (EL33-BIO01). Throughout this protocol, every care was taken to minimize suffering and the number of animals used.

\section{In vivo conditioning - Prenatal ethanol exposure}

Drinking water of three-month old female nulliparous rats was replaced by a $10 \% \mathrm{v} / \mathrm{v}$ ethanol in water solution for one week, and then increased to $15 \%$ for a second week. A male rat was then introduced to the female's cage in order to breed; drinking water remained the $15 \% \mathrm{v} / \mathrm{v}$ ethanol solution throughout breeding and gestation. Each female was housed alone after a pregnancy was confirmed. Ethanol concentration was gradually reduced after parturition (postnatal day 0, PND 0) and was replaced by clean water at PND 15. Pups were separated from the dam at PND 21 and were housed separately, according to sex. These were the "PAE" animals and were sacrificed at PND 21-35 (young) or PND 90-120 (adult) for the preparation of hippocampal slices, with agematched untreated animals as controls (Normal, N).

\section{Brain slice preparation}

Animals were decapitated under deep diethylether (SigmaAldrich) anesthesia, the brains were quickly removed, and the hippocampi isolated. Transverse, $450 \mu \mathrm{m}$ thick slices from the septal and temporal hippocampal extremities were prepared using a Mcllwain Chopper; their anatomical location was also verified 
under the stereoscope by the shape of the dentate gyrus blade (Andersen, 2006). Throughout the preparation process, the brain tissue was hydrated by cool $\left(4^{\circ} \mathrm{C}\right)$, oxygenated $\left(95 \mathrm{O}_{2} / 5 \mathrm{CO}_{2} \%\right)$ artificial cerebrospinal fluid (ACSF) of the following composition (in $\mathrm{mM}$ ): $\mathrm{NaCl} 124, \mathrm{KCl} 2, \mathrm{KH}_{2} \mathrm{PO}_{4} 1.25, \mathrm{CaCl}_{2} 2, \mathrm{MgSO}_{4} 2, \mathrm{NaHCO}_{3} 26$, glucose 10 (all reagents from Sigma), at pH 7.4. Hippocampal slices were then placed in two independent interface chambers (Haas et al., 1979) and were perfused with heated $\left(32 \pm 1^{\circ} \mathrm{C}\right)$ oxygenated standard ACSF replaced by one with no added $\mathrm{Mg}^{2+}\left(\mathrm{Mg}^{2+}\right.$-free ACSF, $1^{\text {st }}$ set of experiments) or one containing $50 \mu \mathrm{M} 4-\mathrm{AP}\left(2^{\text {nd }}\right.$ set of experiments) and were allowed to equilibrate for at least 1 $\mathrm{h}$ before the onset of recording. For the 3rd set of experiments, conducted in $\mathrm{Mg}^{2+}$-free ACSF, the concentration of $\mathrm{KCl}$ in the ACSF was increased to $7 \mathrm{mM}$. The numbers of hippocampal slices per group and the numbers of animals they originated from were as follows: young, $\mathrm{N} n=75$ slices/31 animals, PAE $n=84$ slices $/ 34$ animals; adult $\mathrm{N} n=40$ slices $/ 25$ animals, PAE $n=37$ slices $/ 20$ animals.

\section{Extracellular recordings}

Extracellular recordings from the CA1 pyramidal layer of septal or temporal hippocampal slices were made with $4 \mathrm{M} \mathrm{NaCl}$-filled borosilicate glass micropipettes. Signals were amplified (AxoClamp 2B, Axon Instruments), stored in a PC and analyzed later from digital traces (program Clampfit). Data recording started $\leq 30$ min after the electrode positioning and consisted of a 10 min continuous period for each stage of the experiment. In the high $\mathrm{K}^{+}$protocol, control data $\left(\mathrm{Mg}^{2+}\right.$-free $\left.\mathrm{ACSF}\right)$ were recorded immediately before the onset of increased $\mathrm{K}^{+}$perfusion, and test data $15 \mathrm{~min}$ following the onset of increased $\mathrm{K}^{+}$, after a steady state response had been established. IED frequency was measured for the whole of the recording, whereas the duration of the positive IED field potential $(\mathrm{ms})$ and the $1^{\text {st }}$ population spike amplitude $(\mathrm{mV})$ were averaged from 15 successive events, or the max available number, if fewer.

\section{Substances}

The $\mathrm{I}_{\mathrm{A}}$ current blocker, 4-AP $(50 \mu \mathrm{M})$ was diluted in distilled water to 100 times its final concentration and stored in frozen aliquots, each of which was thawed once and diluted in ACSF to the final 4-AP concentration.

\section{Statistics}

Data are expressed as mean \pm S.E.M. Statistical comparisons between two groups were performed by the paired or unpaired sample Student's t-test, as required. $P$ values were replaced by stars in the figures as follows: * $P<0.05$, ** $P \leq 0.01$, *** $P \leq 0.001$, $\star \star \star \star ~ P \leq 0.0001$; $P$ values $\geq 0.05$ were considered non-significant (n.s.). Statistics were based on the number of slices per group; however, the number of animals is also mentioned, separated by a slash (for example $n=10 / 9$ indicates ten slices from nine animals).

\section{Author contributions}

M.-E. E. Experiments; Formal analysis; Visualization; Writing - original draft sections; C.P. Conceptualization; Methodology (in vivo model); Writing.

\section{Acknowledgments}

Funded by Departmental sources.

Conflicts of interest

No conflict of interest to report.

\section{References}

ABBOTT C. W., KOZANIAN O. O., KANAAN J., WENDEL K. M., HUFFMAN K. J. (2016) The Impact of Prenatal Ethanol Exposure on Neuroanatomical and Behavioral Development in Mice. Alcoholism: Clinical and Experimental Research 40:122-133. https://doi.org/10.1111/acer.12936

ADHIKARI A., TOPIWALA M. A., GORDON J. A. (2010). Synchronized Activity between the Ventral Hippocampus and the Medial Prefrontal Cortex during Anxiety. Neuron 65: 257-269. https://doi.org/10.1016/j.neuron.2009.12.002

ALLAN A. M., CHYNOWETH J., TYLER L. A., CALDWELL K. K. (2003). A Mouse Mode of Prenatal Ethanol Exposure Using a Voluntary Drinking Paradigm. Alcoholism: Clinical \& Experimental Research 27: 2009-2016. https://doi.org/10.1097/01. ALC.0000100940.95053.72

ANDERSEN P., MORRIS R., AMARAL D., BLISS T., O'KEEFE J. (Eds) (2006). The Hippocampus Book. Oxford University Press (OUP). https://doi.org/10.1093/ac prof:oso/9780195100273.001.0001

BELL S. H., STADE B., REYNOLDS J. N., RASMUSSEN C., ANDREW G., HWANG P. A., CARLEN P. L. (2010). The Remarkably High Prevalence of Epilepsy and Seizure History in Fetal Alcohol Spectrum Disorders. Alcoholism: Clinical and Experimental Research 34: 1084-1089. https://doi.org/10.1111/j.1530-0277.2010.01184.x

BERMAN R. F., HANNIGAN J. H. (2000). Effects of prenatal alcohol exposure on the hippocampus: Spatial behavior, electrophysiology, and neuroanatomy. Hippocampus 10:94-110. https://doi.org/10.1002/(SICI)1098-1063(2000)10:1<94::AIDHIP011>3.0.C0;2-T

BLANCHARD B. (1987). Deficits on a spatial navigation task following prenatal exposure to ethanol. Neurotoxicology and Teratology 9: 253-258. https://doi. org/10.1016/0892-0362(87)90010-9

CAMFIELD C., CAMFIELD P. (2007). Preventable and Unpreventable Causes of Childhood-Onset Epilepsy Plus Mental Retardation. Pediatrics 120: e52-e55. https://doi.org/10.1542/peds.2006-3290

CHOI I. Y., ALLAN A. M., CUNNINGHAM L. A. (2005). Moderate Fetal Alcohol Exposure Impairs the Neurogenic Response to an Enriched Environment in Adult Mice. Alcoholism: Clinical \& Experimental Research 29: 2053-2062. https://doi. org/10.1097/01.alc.0000187037.02670.59

CULLEN C. L., BURNE T. H. J., LAVIDIS N. A., MORITZ K. M. (2014). Low Dose Prenatal Alcohol Exposure Does Not Impair Spatial Learning and Memory in Two Tests in Adult and Aged Rats. PLoS ONE 9: e101482. https://doi.org/10.1371/ journal.pone.0101482

DODGE N. C., THOMAS K. G. F., MEINTJES E. M., MOLTENO C. D., JACOBSON J. L., JACOBSON S. W. (2020). Reduced Hippocampal Volumes Partially Mediate Effects of Prenatal Alcohol Exposure on Spatial Navigation on a Virtual Water Maze Task in Children. Alcoholism: Clinical and Experimental Research 44: 844855. https://doi.org/10.1111/acer.14310

FANSELOW M. S., DONG H.W. (2010). Are the Dorsal and Ventral Hippocampus Functionally Distinct Structures?. Neuron 65: 7-19. https://doi.org/10.1016/j. neuron.2009.11.031

GILBERT M., RACINE R.J., SMITH G.K. (1985). Epileptiform burst responses in ventral vs dorsal hippocampal slices. Brain Research 361: 389-391. https://doi. org/10.1016/0006-8993(85)91309-5

GÓMEZ R. L., EDGIN J. O. (2016). The extended trajectory of hippocampal development: Implications for early memory development and disorder. Developmental Cognitive Neuroscience 18: 57-69. https://doi.org/10.1016/j.dcn.2015.08.009

HAAS H.L., SCHAERER B., VOSMANSKY M. (1979). A simple perfusion chamber for the study of nervous tissue slices in vitro. Journal of Neuroscience Methods 1: 323-325. https://doi.org/10.1016/0165-0270(79)90021-9

IERACI A., HERRERA D. G. (2007). Single alcohol exposure in early life damages hippocampal stem/progenitor cells and reduces adult neurogenesis. Neurobiology of Disease 26: 597-605. https://doi.org/10.1016/j.nbd.2007.02.011

JONES M. W., MCHUGH T. J. (2011). Updating hippocampal representations: CA2 joins the circuit. Trends in Neurosciences 34: 526-535. https://doi.org/10.1016/j. tins.2011.07.007

KESMODEL U. S., NYGAARD S. S., MORTENSEN E. L., BERTRAND J., DENNY C. H., GLIDEWELL A., ASTLEY HEMINGWAY S. (2019). Are Low-to-Moderate Average Alcohol Consumption and Isolated Episodes of Binge Drinking in Early Pregnancy Associated with Facial Features Related to Fetal Alcohol Syndrome in 5-Year-Old Children?. Alcoholism: Clinical and Experimental Research 43: 1199-1212. https:// doi.org/10.1111/acer.14047 
KOFUJI P., NEWMAN E.A. (2004). Potassium buffering in the central nervous system. Neuroscience 129: 1043-1054. https://doi.org/10.1016/j.neuroscience.2004.06.008

LINDBLOM N., HEISKALA H., KASKI M., LEINONEN L., NEVANLINNAA., IIVANAINEN M., LAAKSO M.L. (2001). Neurological impairments and sleep-wake behaviour among the mentally retarded. Journal of Sleep Research 10: 309-318. https://doi. org/10.1046/j.1365-2869.2001.00267.x

LIVY D.J., MILLER E.K., MAIER S. E., WEST J. R. (2003). Fetal alcohol exposure and temporal vulnerability: effects of binge-like alcohol exposure on the developing rat hippocampus. Neurotoxicology and Teratology 25: 447-458. https://doi. org/10.1016/S0892-0362(03)00030-8

MIKROULIS A., LISGARAS C. P., PSARROPOULOU C. (2018). Immature Status Epilepticus: In Vitro Models Reveal Differences in Cholinergic Control and HFO Properties of Adult CA3 Interictal Discharges in Temporal vs Septal Hippocampus. Neuroscience 369:386-398. https://doi.org/10.1016/j.neuroscience.2017.11.029

MIKROULIS A. V., PSARROPOULOU C. (2012). Endogenous ACh effects on NMDAinduced interictal-like discharges along the septotemporal hippocampal axis of adult rats and their modulation by an early life generalized seizure. Epilepsia 53: 879-887. https://doi.org/10.1111/j.1528-1167.2012.03440.x

MOSER M.B., MOSERE. I. (1998). Functional differentiation in the hippocampus. Hippocampus 8: 608-619. https://doi.org/10.1002/(SICI)1098-1063(1998)8:6<608::AIDHIPO3>3.0.C0;2-7

O'MALLEY K. D., BARR H. (1998). Fetal alcohol syndrome and seizure disorder. Canadian journal of psychiatry. Revue canadienne de psychiatrie 43: 1051.

PAPATHEODOROPOULOS C., ASPRODINI E., NIKITA I., KOUTSONA C., KOSTOPOULOS G. (2002). Weaker synaptic inhibition in CA1 region of ventral compared to dorsal rat hippocampal slices. Brain Research 948: 117-121. https://doi. org/10.1016/S0006-8993(02)02958-X

PAPATHEODOROPOULOS C., KOSTOPOULOS G. (2002). Spontaneous GABAAdependent synchronous periodic activity in adult rat ventral hippocampal slices. Neuroscience Letters 319:17-20. https://doi.org/10.1016/S0304-3940(01)02505-8
PAPATHEODOROPOULOS C., MOSCHOVOS C., KOSTOPOULOS G. (2005) Greater contribution of N-methyl-d-aspartic acid receptors in ventral compared to dorsal hippocampal slices in the expression and long-term maintenance of epileptiform activity. Neuroscience 135: 765-779. https://doi.org/10.1016/j. neuroscience.2005.06.024

PATTEN A. R., FONTAINE C. J., CHRISTIE B. R. (2014). A Comparison of the Different Animal Models of Fetal Alcohol Spectrum Disorders and Their Use in Studying Complex Behaviors. Frontiers in Pediatrics 2: 93. https://doi.org/10.3389/ fped.2014.00093

PAULA-BARBOSA M. M., BRANDAO F., MADEIRA M. D., CADETE-LEITE A. (1993) Structural changes in the hippocampal formation after long-term alcohol consumption and withdrawal in the rat. Addiction 88: 237-247. https://doi. org/10.1111/j.1360-0443.1993.tb00807.x

PSARROPOULOU C., AVOLI M. (1996). Developmental features of 4-aminopyridine induced epileptogenesis. Developmental Brain Research 94: 52-59. https://doi. org/10.1016/0165-3806(96)00040-5

SCHWARTZKROIN P. A. (1982). Development of rabbit hippocampus: Physiology. Developmental Brain Research 2: 469-486. https://doi.org/10.1016/0165 3806(81)90017-1

SCHWARTZKROIN P. A., KUNKEL D. D., MATHERS L. H. (1982). Development of rabbit hippocampus: Anatomy. Developmental Brain Research 2: 453-468. https:// doi.org/10.1016/0165-3806(81)90016-X

SPOHR H., STEINHAUSEN H. (1987). Follow-Up Studies of Children with Fetal Alcohol Syndrome. Neuropediatrics 18: 13-17. https://doi.org/10.1055/s-2008-1052428

TARELO-ACUÑA L., OLVERA-CORTÉS E., GONZÁLEZ-BURGOS I. (2000). Prenatal and postnatal exposure to ethanol induces changes in the shape of the dendritic spines from hippocampal CA1 pyramidal neurons of the rat. Neuroscience Letters 286: 13-16. https://doi.org/10.1016/S0304-3940(00)01075-2

TOYODA I., BOWER M. R., LEYVA F., BUCKMASTER P. S. (2013). Early Activation of Ventral Hippocampus and Subiculum during Spontaneous Seizures in a Rat Model of Temporal Lobe Epilepsy. Journal of Neuroscience 33: 11100-11115. https://doi.org/10.1523/JNEUROSCI.0472-13.2013 